\title{
Gestão da vida a partir do esporte e lazer em Grigny Centre - França
}

José Damico*

\begin{abstract}
Resumo: O artigo é parte de uma tese de doutorado que analisou determinadas formas de governamento da juventude através do esporte e do lazer em Grigny Centre (súburbio de Paris). A abordagem situa-se na interface dos estudos de gênero e da antropologia política, as perspectivas que propõem uma aproximação crítica com a teorização foucaultiana. Constituíram fontes de pesquisa: documentos de imprensa; anotações das recordações de campo e entrevistas. Os materiais foram analisados na perspectiva da análise cultural. As ações de prevenção dirigidas à juventude pobre na periferia de Paris que utilizam o esporte e lazer prescrevem normas e representações de condutas juvenis consideradas adequadas.
\end{abstract}

Palavras-chave: Violência. Atividades de Lazer.

\section{LocAlizANDO A TEMÁTICA}

Este artigo é parte de uma tese de doutorado ${ }^{1}$ que analisa determinadas formas de governamento da juventude através de políticas de segurança pública, entendendo-as como respostas do Estado à expansão e à generalização de um sentimento de insegurança e medo na sociedade contemporânea.

Para tanto, discuto práticas de governamentalidade implementadas pelo Estado francês para subúrbios considerados difíceis como Grigny Centre na periferia de Paris. Essas práticas ocorrem através da oferta de atividades, principalmente de cunho esportivo $^{2}$, no âmbito das chamadas politiques de la ville.

\footnotetext{
'Doutor em Educação e Professor da ESEF/UFRGS e do Programa de Pós Graduação em Educação e Ciências (Furg), E-mail: zdamico@yahoo.com.br

${ }^{1} \mathrm{O}$ autor do presente artigo recebeu auxílio em forma de bolsa da CAPES.

${ }^{2}$ Para ver análises críticas sobre políticas (programas ou projetos) sociais de inclusão de esporte e lazer no âmbito brasileiro destaco os artigos publicados nesse periódico: MELO (2005), THOMASSIM (2007); VIANNA; LOVISOLO (2009); HECKTHEUR; SILVA (2011).
} 
A abordagem teórico-metodológica situa-se na interface dos estudos de gênero, dos estudos culturais e da antropologia política, principalmente as perspectivas que propõem uma aproximação crítica com a teorização foucaultiana; o trabalho posiciona-se no campo de uma etnografia pós-moderna, a partir de uma combinação de metodologias e de modos de escrita.

Constituíram fontes de pesquisa: documentos de órgãos de imprensa; anotações das recordações de campo, grupos de discussão e entrevistas. Os materiais foram analisados na perspectiva da análise cultural, ancorada na teorização foucaultiana. O trabalho de campo foi realizado entre março de 2009 e janeiro de 2010. Em Grigny Centre, realizei 10 entrevistas com jovens, três mulheres e sete homens, para complementar as informações não tratadas nos grupos de discussões.

\section{Grigny Centre uma cidade explosiva}

A maioria dos prédios tem em torno de 11 andares, com antenas parabólicas presas às paredes e cordas nas varandas onde se penduram todos os tipos de coisas. Eles correspondem muito bem às imagens que tenho visto dos subúrbios parisienses na mídia. Para minha surpresa, quando saio da estação e olho para a direita em direção a Grigny II, vejo pelo menos 10 veículos grandes da polícia francesa, muitos policiais perfilados e bem armados, com equipamentos de proteção (ombreiras, joelheiras, cotoveleiras pretas) - um vestuário que, até agora, só tinha visto em filmes de ficção. Ao mesmo tempo, pessoas caminhavam tranquilamente, sozinhas ou em grupos, às vezes compostos por famílias numerosas com vários carrinhos para bebês. Não aguentei e perguntei para um garoto de 12 anos se tinha acontecido alguma coisa que justificasse a presença de tantos policiais, e ele me respondeu com muita tranquilidade que não, que aquilo era normal: C'est normal. [Recordações de campo, Grigny Centre, 7 maio 2009]. 
Atualmente, o território que foi concebido para ser um bairro tranqüilo e moderno é representado como uma das zonas mais pobres e mais difíceis dos subúrbios de Paris. Segundo a mídia, o Estado francês e grande parte dos trabalhos acadêmicos que se ocupam de problemáticas que envolvem violência, migração e exclusão social, é um dos mais explosivos subúrbios franceses em função dos confrontos $^{3}$ com a polícia. A maioria dos habitantes acima dos 40 anos veio da região de $\mathrm{Magreb}^{4}$ ou da África sub-saariana ${ }^{5}$. Os mais jovens são, na sua maioria, nascidos na França.

Além das habitações degradadas, em boa parte dos prédios os elevadores não funcionam, e são comuns casos de famílias com mais de dez crianças que vivem em um apartamento de três quartos. A cidade tem uma das maiores taxas de desemprego de toda a França, chegando a quase $50 \%$ para jovens entre 15 e 24 anos. Para a população geral essa taxa é de 30\% (KOKOREFF, 2003).

São, justamente, características como forte densidade populacional, concentração de população estrangeira, grande proporção de jovens com menos de 30 anos, taxas de desemprego maiores do que a média nacional, altos índices de fracasso e evasão escolares, bem como a perceptível tensão entre diferentes grupos sociais, que são utilizadas para nomear subúrbios parisienses como esse de subúrbios sensíveis, desfavorecidos, difíceis e violentos.

Muitos desses discursos sugerem o endurecimento de penas prisionais e a redução da maioridade penal e são tão potentes que é difícil argumentar na contramão da contundêcia e assertividade com que estatísticas e fatos deles derivados são apresentados.

Até o início dos anos 1970, os bairros e os subúrbios populares na França foram relegados espacialmente, mas muitas vezes estruturados em relação às questões políticas, sindicais e culturais.

\footnotetext{
${ }^{3}$ Os "eméutes" como são denominados tais confrontos tem como característica a reação dos jovens a algum abuso por parte da polícia e resulta em carros queimados, saques e prisões.

${ }^{4}$ Argélia, Tunísia, Líbia, Mauritânia, Saara Ocidental e Marrocos.

${ }^{5} \mathrm{~A}$ cidade, segundo os próprios moradores, está dividida entre a população de origem africana, que vive em La Grand Borne, e a população de origem árabe, que vive em Grigny II.
}

Movimento, Porto Alegre, v. 19, n. 01, p. 11-31, jan/mar de 2013. 
Nesse sentido, um conjunto de práticas sociais de esporte e lazer esteve ligada ao que se convencionou chamar de uma solidariedade de classe, como jogar futebol, jogar boliche, pescar e se reunir em festas comunitárias.

Atualmente, essas áreas são consideradas de relegação espacial (CASTEL, 2007) e são frequentemente associadas à ideia de desintegração das camadas populares. Em função dessas representações negativas, diversos serviços privados e públicos desapareceram, como clubes esportivos, apoio as atividades de férias escolares, diminuição no número de animadores sociais e a atividade comercial foi diminuída gradualmente. Para os moradores desses lugares, restaram as associações de bairro e os dispositivos municipais de animação esportiva de proximidade.

Na próxima seção apresento, num primeiro momento, uma descrição suscinta das politiques de la ville e das práticas de esporte e lazer em Grigny Centre, para depois analisar dois espaços implicados em incentivar, organizar e ocupar jovens através das práticas esportivas e de lazer: a Associação Vivacité e o Centro de Juventude, ambos criados como equipamentos de prevenção à violência.

\section{EU COSTUMO DIZER AOS JOVENS: COMECE A TREINAR, APRENDA E DEPOIS, SE QUISER, PODE IR EMBORA}

Desde a década de 1980, as políticas de prevenção reunem uma variedade de práticas que tendem a agir sobre as causas da delinquência (prevenção social), ou impedir a passagem ao ato (chamada de prevenção situacional). Considerando que a prevenção social teve algum sucesso na década de 1980, a prevenção situacional hoje parece ter assumido o lugar hegemônico. No entanto, em vários países europeus, a prevenção social continua a ser invocada por muitos intervenientes sociais baseados em subúrbios populares considerados como "criminogênicos". 
Vários dispositivos de intervenção foram criados com a intenção de promover a revitalização econômica, a melhoria das condições de habitação, a formação profissional ou de empregabilidade de jovens residentes em Grigny Centre. Além disso, esses dispositivos funcionam como parte da formulação de novas práticas de intervenção social: em resposta à exclusão social no contexto das politiques de la ville.

As politiques de la ville objetivaram e objetivam a renovação das habitações, a melhoria dos espaços públicos e o desenvolvimento das atividades para ocupar os jovens por meio do esporte e lazer. Incluiu mudanças legislativas e planejamento urbano, em parceria com as autoridades locais, muitas vezes baseado em um contrato entre o Estado francês, o departamento e o município.

O governo criou cursos e carreiras para educadores/as e animadores/as sociais nos subúrbios, com objetivo de que esses/as novos/as colaboradores/as pudessem estabelecer relações de confiança que promovessem laços sociais, a participação dos moradores, apoio às iniciativas associativas e comunitárias etc.

Os/as educadores/as e animadores/as sociais ocupam uma posição estratégica em Grigny Centre devido ao conhecimento que têm do público-alvo e seu savoir-faire em termos de negociação e manutenção das redes sociais.

Do ponto de vista de sua atuação, os/as educadores/as sociais estariam situados/as na fronteira entre o campo da mediação social e de vigilância, com as atividades extracurriculares: esportes, atividades de lazer durante o período de férias escolares, atividades diversificadas, esportes recreativos. As intervenções obedecem a programas concentrados nas áreas de cultura e esportes. No caso da cultura, procura-se a ampliação dos laços identitários e o entretenimento da população, sendo priorizada a implantação de bibliotecas e centros de juventudes. Um segundo grupo de intervenções consistiu na ampliação da oferta de locais para a prática de esportes, na implantação de campos de futebol, quadras esportivas e piscinas, com a intenção de atrair a população jovem. 
No início da década de 1980, o governo francês buscou selecionar os/as educadores/as sociais entre as lideranças dos próprios grupos de jovens, esperando que esses pudessem exercer controle sobre as bandas e galeras dos bairros.

Em relação aos equipamentos públicos de animação para jovens, Grigny Centre conta 11 equipamentos esportivos (uma piscina, oito ginásios e dois complexos esportivos externos), duas bibliotecas para jovens e um centro de juventude.

No bairro Guajuviras em Canoas onde funciona o Pronasci ${ }^{6}$ com a ressalva do pouco tempo que vigoram as políticas de segurança por lá - bolsistas, monitores e toda sorte de subcategorias têm a mesma função de mediação, mas são precarizados em termos de remuneração. Sabem que, provavelmente, seu tempo de atuação será muito curto, o que os torna reféns das disputas partidárias e das intenções dos gestores dos projetos. O contrário ocorre em Grigny ${ }^{7}$, uma vez que os/as educadores têm uma carreira mais reconhecida e a garantia de um tempo maior de permanência. A vulnerabilidade dos/as educadores/as em relação aos interesses estatais parece ser bem menor. Registro, abaixo, um dos diálogos que tive com um desses animadores sociais:

Damico: Abdala, como funciona tua relação com a Maire? Abdala: A relação é boa, porque eles sabem que farei tudo que puder para ajudar os jovens e que não farei nada que eu julgue que possa prejudicar os jovens.

Damico: Como assim? Abdala: Aqui em Grigny a pior coisa é a traição. Eu conheço muito bem as regras do bairro, e não vou ferir essas regras para agradar $\mathrm{A}$ ou $\mathrm{B}$, senão eu não poderia dormir à noite, ou até mesmo morar aqui. [Entrevista, Abdala, 23 jul. 2009].

\footnotetext{
${ }^{6}$ Programa Nacional de Segurança de e Cidadania de Canoas é considerado modelo de sucesso para o restante do país.

${ }^{7}$ As impressões que tenho dos educadores sociais de Grigny são influenciadas por Amar Henni, que foi um dos primeiros educadores de lá e que selecionou boa parte dos que estão ainda em atividade.
} 
Nesses contextos, esses/as profissionais têm, em geral, desenvolvido uma ética e cultura profissional específica. Segundo o que pude perceber, tais trabalhadores/as sociais têm uma função fundamental no equilíbrio instável de Grigny, porque são capazes ao mesmo tempo de conter uma revolta ou produzir uma, de acordo com um julgamento hierarquizado da gravidade da situação.

Foi justamente depois da chegada da esquerda ao poder na França, na década de 1980, que o esporte apareceu em relação aos jovens das periferias como um meio de canalizar sua violência e como modo de facilitar sua integração à sociedade francesa. Os jovens inseridos em equipes esportivas encontrariam outro meio social. A ideia é a mesma com que convivemos no Brasil sobre determinadas características que seriam intrínsecas ao próprio esporte, como disciplina, sociabilidade, autocontrole, entre tantas outras.

Em Grigny, pude observar uma diversificação das práticas esportivas. Alguns esportes que quase não existem no Brasil, principalmente nos meios populares, como rugby e hóquei sobre patins, além de esportes bastante comuns como futebol, basquete e as lutas.

Fatores como idade, sexo e a situação empregatícia são variáveis que colaboram para constituir determinadas práticas; atuam como linhas divisórias nas atividades esportivas dos meios populares. Os trabalhadores autônomos ou que têm atividades muito precárias enfrentam um ritmo frenético, ligando o tempo de trabalho (incluindo o tempo de deslocamento para quem trabalha em Paris, que pode durar até uma hora e meia) e o de uma vida familiar intensa. Como exemplos, um jovem de 29 anos que atua numa empresa de telemarketing ou outro de 24 anos, que atua de modo terceirizado numa empresa de telefonia. Conversei com eles durante o trabalho de campo, e ambos disseram que têm grandes dificuldades de se inserir nas atividades esportivas em função dos horários de trabalho. Essas restrições parecem ser mais visíveis como contingência das condições de trabalho impostas atualmente, que tornaram a atividade profissional caótica e irregular. 
Somente os assalariados dos meios populares conseguem aderir mais regularmente às práticas de esportes: esses trabalhadores ou pequenos empregados que atuam no próprio bairro conseguem manter uma prática de caminhada, ginástica, natação, atletismo, esportes coletivos, principalmente futebol e basquetebol. Portanto sexo, idade e situação de emprego combinam-se para especificar as práticas e definir os perfis dos indivíduos que praticam o lazer esportivo em Grigny Centre.

Para além dessa análise mais geral das disposições dos habitantes de Grigny Centre em relação às suas práticas esportivas, analiso a seguir dois espaços e que funcionam, no meu entender, como dispositivos de governamento: trata-se da Associação Vivacité e o Centro de Juventude.

Estive diversas vezes na Associação Vivacité, que tem sob sua supervisão a animação de práticas esportivas, entre elas a musculação, a ginástica e as lutas (judô, jiu-jitsu, wrestling, boxe). A frase com que abro esta subseção é de Amhed (Jo, como é conhecido): "Eu costumo dizer aos jovens: comece a treinar, aprenda e depois, se quiser, pode ir embora". Ele é um dos fundadores e grande responsável pelo funcionamento da associação que atrai centenas de jovens em torno de um ginásio instalado ao lado do bairro de La Grande Borne. Em uma matéria do Jornal Libération, Jo afirma:

[...]As pessoas aqui, quando elas não conhecem, elas são desconfiadas e cautelosas e com razão, muitas pessoas já exploraram demais as pessoas daqui. Nossa associação trouxe muitos jovens que participam das atividades desportivas. Mas não adianta ter uma sala de fitness sem nada no cérebro, é inútil. Aqui, as pessoas trabalham com regras. [...] Um jovem, para não fazer besteiras, ele deve ter regras e dar um sentido à sua vida. Nós procuramos os jovens nas galeras ${ }^{8}$. Há um trabalho de integração a ser feito mediado pelos esportes, para depois encaminhá-los para os profissionais com uma

${ }^{8}$ Grupos de jovens que se reunem para cometer pequenos delitos.

Movimento, Porto Alegre, v. 19, n. 01, p. 11-31, jan/mar de 2013. 
assistente social, as missões locais e os equipamentos de animação. [Journal Libération, 7 jun. 2005].

Esse depoimento foi dado por $\mathrm{Jo}^{9}$ pelo menos quatro anos antes de eu conhecê-lo e ele segue acreditando na filosofia do regramento e das normas como uma espécie de libertação dos jovens através do aprendizado que o esporte pode proporcionar. No entanto chama a atenção que Jo faz referência ao cérebro, ou seja, a inteligência valoriza a relação dialógica entre sua função de animador e o jovem.

Minha aproximação com Jo e outros educadores sociais e até mesmo com jovens era facilitada pelo modo como Amar me apresentava. Além de sempre repetir que eu fazia um trabalho de pesquisa semelhante ao dele, ele dizia que eu era professor de educação física e especialista em esportes. Eu me aproveitava, no bom sentido, para começar conversas sobre determinado esporte ou atleta que pudéssemos ambos conhecer. [Recordações de campo, 20 mai. 2009].

Quando o entrevistei, ele reforçou tais posições e, ao contrário das posições com as quais me deparei com os animadores do Território de Paz no Guajuviras, que defendiam as qualidades intrínsecas do esporte, Jo não cansava de dizer:

O esporte eu utilizo como meio, meio para o diálogo, meio para que eles não sejam presos ou façam besteiras, e meio quem sabe de mobilidade social. Aqui todos sabem das regras e os mais velhos ajudam os mais novos a cumpri-las. [Entrevista, Jo, educador, 6 jul 2009].

Jo define, sem rodeios, que é através de todo um código moral, combinado com um conjunto de técnicas disciplinares (dentre elas o exame permanente das condutas dos/das jovens), que a conduta moral dos/as jovens pode ser (re)construída. Michel Foucault define a técnica do exame deste modo:

\footnotetext{
${ }^{9}$ Dos todos os interlocutores, Ahmed (Jo) é o único que não utilizo um nome fictício atendendo a seu pedido.
}

Movimento, Porto Alegre, v. 19, n. 01, p. 11-31, jan/mar de 2013. 
O exame combina as técnicas da hierarquia que vigia e as da sanção que normaliza. É um controle normalizante, uma vigilância que permite qualificar, classificar e punir. Estabelece sobre os indivíduos uma visibilidade através da qual eles são diferenciados e sancionados. É por isso que, em todos os dispositivos de disciplina o exame é altamente ritualizado. Nele vêm-se reunir a cerimônia do poder e a forma da experiência, a demonstração da força e o estabelecimento da verdade (FOUCAULT, 1989, p. 154).

A posição de Jo, como ídolo e liderança ${ }^{10}$ dos jovens, permite que ele possa coordenar um espaço que está todo o tempo sob o exame da vigilância. Aliás, entendo que a posição de sujeito que Jo ocupa é legitimada no campo das artes marciais, e não no discurso acadêmico da educação física. Diferente do ocorre no Brasil em relação à educação física enquanto uma área bastante consolidada, permitindo que seu discurso especializado seja hegemônico, na França a educação física restringe-se quase à educação escolar. Em outros espaços, como as associações, é exigida uma espécie de certificação de alguma área específica. No caso de Jo, ele é certificado em treinamento de artes marciais.

Julio Perciúncula (2007) considera que a filosofia do judô ocidental e atual, por exemplo, está muito mais próxima da filosofia cartesiana, do pensamento iluminista e da lógica liberal do que com as filosofias orientais antigas:

Ao considerarmos que o judô moderno nasce no período da europeização japonesa, na segunda metade do século XIX, é que podemos pensar no quanto esta prática guarda semelhanças com as

\footnotetext{
${ }^{10} \mathrm{Em}$ geral, essas práticas de intervenção desenvolveram-se independentemente à polícia, ou até mesmo em oposição, quando por exemplo numa situação de confronto com a polícia Jo vai ficar do lado dos jovens e inclusive pode liderá-los.
} 
práticas corporais européias que foram esportivizadas; o judô moderno é a esportivização do antigo jiu-jitsu e como os demais esportes modernos seu foco foi desde o início voltado para o controle da violência física, para a individualização e para a constituição de sujeitos auto-regulados, autônomos e autodisciplinados, em uma palavra autogovernados. (PERCIÚNCULA, 2007, p. 85).

Não por acaso, o Vivacité tem as artes marciais ${ }^{11}$ como carrochefe entre suas atividades. Para produzir sujeitos autogovernados, as artes marciais fazem uso de toda uma metodologia de saberes que vão desde as cores das faixas - que diferenciam seus praticantes pelo nível de aprendizado - a códigos de conduta durante treinos e competições, código de honra que interdita as lutas fora das arenas próprias para esse uso, categorias divididas em função do peso e da idade dos praticantes, que conduz ao que Fraçois Dubet (2003) define como a ficção da justiça no âmbito esportivo. Ou seja, há toda uma utilização de tecnologias disciplinares para a normalização e o desenvolvimento adequado de seus praticantes.

Nessa direção, as lutas esportivizadas representariam a capacidade de dominar o outro e abatê-lo. Entre os praticantes das lutas marciais, o exercício da violência física é submetido e controlado pelo respeito às regras relativas à preservação da vida do adversário, produzindo o orgulho de ser autocontrolado pela ética esportiva e colocando o conflito e a rivalidade em outra dimensão.

\footnotetext{
${ }^{11}$ Lutas ou esportes de combate, como tem se convencionado chamar na Educação Física Brasileira.
}

Movimento, Porto Alegre, v. 19, n. 01, p. 11-31, jan/mar de 2013. 
Figura 1 - Jornal informativo da Maire de Grigny Centre, com destaques aos feitos desportivos de atletas locais.

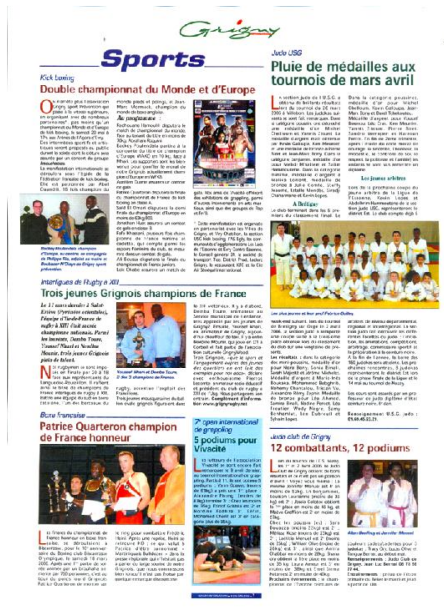

Fonte: autor

Uma das dimensões a que Jo se referiu é a possibilidade de mobilidade social através do esporte. Do que sabemos em relação ao Brasil em termos de projetos sociais, estes utilizam muitas vezes esse argumento sub-repticiamente como modo de alimentar o sonho de melhoria de vida dos jovens, mas quando são abordados diretamente defendem a dimensão recreativa da prática esportiva. No Vivacité, mesmo o esporte sendo definido como um meio, nas palavras de Jo, o treinamento visa ao esporte de competição ${ }^{12}$. É possível depreender que no Vivacité a hierarquia da aprendizagem está pautada na conduta, no treinamento e no corpo; o discurso sobre as possibilidades de prazer não encontra espaços quando se está em luta contra o Estado.

Agentes como Jo que conhecem seu território e são conhecidos e respeitados ocupam uma posição estratégica para a manutenção de redes de todos os tipos. Além disso, estes dispositivos constituem a base para a formulação de novas práticas de intervenção social:

\footnotetext{
${ }^{12} \mathrm{O}$ Vivacité sustenta com orgulho campeões europeus de boxe, judô e jiu-jitsu, além de vicecampeão mundial de jiu-jitsu e vários campeões franceses de diferentes modalidades de lutas.
} 
em resposta à "exclusão social". Para o Estado francês equipamentos como o Vivacité podem ser uma resposta aos problemas de vizinhança ou a expressão de sentimentos de insegurança, conflito ou até mesmo a fenômenos tidos como de "violência urbana".

Nos subúrbios como Grigny, e em especial no Vivacité, muitos jovens valorizam o corpo musculoso, como um capital importante na orientação das escolhas das práticas esportivas, como os desportos de combate e os esportes coletivos considerados viris, como o rugby (DUBET, 1987; LEPOUTRE, 1997).

"Eu costumava lutar muito antes, quando eu era mais jovem. Fiquei ainda mais forte do que sou agora, porque eu estava treinando o tempo todo: boxe tailandês, jiu-jitsu e rugby. Eu tinha que ganhar o meu lugar e agora as pessoas me respeitam muito. Eu sou um dos mais respeitados, por isso não tenho que lutar muito mais." [Nourredin, 26 anos].

[ Grupo de discussão em Grigny Centre, 20 jun. 2009].

A força física nos ambientes populares é sagrada e é muitas vezes para os homens jovens o último recurso que pode ser invocado para definir-se socialmente. $\mathrm{O}$ uso de defesa física é inversamente proporcional aos meios de defesa social entre os jovens dos bairros considerados problemáticos.

Um dos aspectos necessários de abordar é que muitos atributos desenvolvidos a partir dos esportes de combate são marcadores tidos como masculinos: força, musculatura desenvolvida e frieza. Édison Gastaldo (1995) observou que, nos esportes de combate, sempre dominaram aspectos simbólicos que envolvem a construção da masculinidade.

Numa das minhas visitas, perguntei se as mulheres não poderiam participar das atividades, uma vez que eu só tinha visto homens. Um dos educadores responsáveis respondeu-me:

Claro que podem e participam, só que elas têm um horário que é só delas. Por quê? Pois não ficaria bem as mulheres fazerem atividades com os homens 
olhando. Muitas são mulheres casadas, mães de família, e até mesmo bem jovens e não seria correto homens e mulheres juntos. Mas não tem mulheres lutadoras? Tem sim, são aquelas que insistem muito, as mais guerreiras mesmo, senão não aguenta o treino. Tem que ter muita força de vontade. Essas logo se tornam campeãs. [Johan, 28 anos, animador Vivacité, 13 jun. 2009].

Fica claro que, no Vivacité, as mulheres jovens só conseguem ocupar um espaço de respeito se adquirem as características consideradas como masculinas, como superação, força de vontade e garra.

\section{AS MULHERES AQUI TEM QUE SE CUIDAR}

O Centro da Juventude é outro espaço de animação de Grigny Centre, onde fizemos todas as reuniões do grupo de discussão. Tem uma ampla sala de informática com pelo menos 12 computadores, uma sala com jogos de mesa como sinuca e fla-flu (pebolim), cozinha e refeitório e uma ampla sala de reuniões. Funciona como um espaço de convivência e debate entre os/as jovens. Os/as animadores/as do Centro da Juventude estão empenhados em organizar cursos e atividades esportivas para os/as jovens.

Lá, frequentam garotos de 12 anos em diante que vão usar a internet e até jovens adultos de 30 anos. As mulheres que frequentam o centro, ou são educadoras ou são jovens com cerca de 18 anos que participam do grupo de dança. Nunca vi nenhuma garota mais jovem durante os meses em que estive frequentando o centro.

Entrevistei três jovens do grupo de dança, e uma delas disseme os motivos para essa participação menor de mulheres:

Por que as mulheres não frequentam mais o Centro?

Porque aqui em Grigny você tem que se cuidar, tem que se dar o respeito. Nós somos de certo modo obrigadas a andar em grupo, uma mulher jovem sozinha não é bem vista. E aqui no centro a grande 
maioria é de homens que passam o dia ali. Além do mais, nós temos outras coisas para fazer, a maioria de nós do grupo estuda, faz estágio ou trabalha. [Aima, jovem de 17 anos, 11 nov. 2009].

Grigny é considerada, por esta e outras jovens com quem conversei, uma cidade bastante vigilante com relação às mulheres jovens. Mas o que Aima disse sobre suas ocupações corresponde também ao que Dubet (2003) salienta sobre o fato de as mulheres conseguirem manter-se mais tempo escolarizadas, mesmo as do subúrbio, que não se rebelam tanto com as normas e tradições da escola francesa, ao mesmo tempo em que suportam melhor as humilhações dos/das professoras/es em relação ao seu jeito de falar e de vestir. Parecem ter claro que o estudo pode possibilitar a saída do subúrbio para uma vida diferente das suas mães. $\mathrm{O}$ autor referese à situação das mulheres na França:

As mulheres dominam os serviços, são majoritárias na educação e na saúde, enquanto que elas não entram na produção, exceto como operárias sem qualificação, na política ou em outros setores que permanecem amplamente masculinos. [...] Assim as mulheres jovens são as grandes beneficiárias da massificação escolar; mas ao mesmo tempo que elas são bem mais sucedidas que os rapazes, elas não se orientam para formações mais lucrativas, especialmente as formações científicas. (DUBET, 2003, p. 40).

Nesse processo, a lógica de exclusão das mulheres jovens nos bairros populares faz com que estádios e ginásios sejam tidos como espaços masculinos. Em algumas situações, à medida que as mulheres ficam mais velhas, especialmente após o período escolar e de educação dos filhos pequenos, pode ocorrer a retomada das atividades de lazer das mulheres. O lazer esportivo continua sendo um espaço reservado aos homens, especialmente os mais jovens. A onipresença masculina empurra as mulheres a permanecerem confinadas tradicionalmente à esfera privada, em especial nas famílias de tradição muçulmana. 
As garotas de até 15 anos participam ativamente das atividades promovidas pelo Centro da Juventude, desde que aconteçam fora daquele prédio que é tomado por homens jovens. No entanto, com o avanço da idade, a maior parte das meninas abandona o esporte. $\mathrm{O}$ abandono das práticas esportivas pelas mulheres jovens é bastante parecido com o que ocorre nas classes populares brasileiras ${ }^{13}$.

\section{FUTEBOL COMO VITRINE}

Uma das principais atividades promovidas pelo Centro são os campeonatos de futebol que, aos moldes do Vivacité, trazem orgulho para os habitantes de Grigny. Para os brasileiros periféricos, seria impensável que equipamentos públicos como o Vivacité e o Centro da Juventude pudessem realizar competições de nível nacional ou internacional do porte das que são realizadas em Grigny. Como o Campeonato Mundial de Kicking Boxe, em 2006, e o Mundial de Jiu-jitsu, em 2010, promovidos e organizados pelo Vivacité. Já o Centro da Juventude organizou em 2006 e 2010 em Grigny a Copa do Mundo de Banlieues (de fut- $5^{14}$ ).

A opção colocada em ação pelos educadores do Vivacité, em relação ao aprendizado e ao treinamento esportivo em termos técnicos, é contrastante com a opção do PELC/Pronasci no bairro Guajuviras, em que se fez a escolha - pelo Ministério do Esporte de abandono de uma perspectiva de aperfeiçoamento sistemático nas técnicas desportivas, optando-se pela ocupação do tempo livre dos jovens, para afastá-los das ruas, das más companhias. No Brasil, priorizou-se a socialização dos jovens através de uma suposta prática esportiva recreativa e prazerosa, na qual os monitores seriam agentes de mediação.

\footnotetext{
${ }^{13} \mathrm{~A}$ investigação Perfil da Juventude Brasileira (organizada pela Fundação Perseu Abramo) aponta que apenas $3 \%$ das mulheres jovens brasileiras entre 15 e 24 anos praticam algum esporte, enquanto até os 15 anos são 34\% (BRENNER; DAYRELL;CARRANO, 2005, p. 179). ${ }^{14} \mathrm{~J}$ ogo semelhante ao futsal.
} 
Quero lembrar que, num dos excertos, Jo se referia a ir buscar os jovens nas galeras. Ou seja, há obviamente uma busca de normalização dos jovens que teriam se perdido.

Tal desvio é observado na França no caso de jovens que romperam com os quadros familiares e escolares e que encontram, no uso desproporcional da força, armas para enfrentar outros jovens e a polícia, como uma forma de poder e reconhecimento no seio de um mundo ilusoriamente considerado fechado, assim como é o subúrbio, um mundo que tem suas próprias regras de honra $\mathrm{e}$ autoridade.
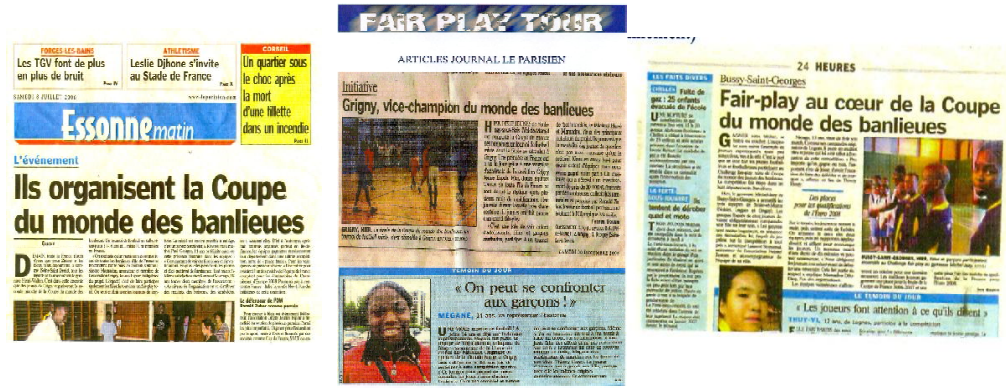

Fonte: autor

\section{Para finalizar...}

Michel Foucault (2008), ao analisar a racionalidade política moderna, defende que a disseminação do sentimento difuso de insegurança é um catalisador fundamental das ações de governo e produz uma responsabilização individual por problemas sistêmicos, ao mesmo tempo em que faz proliferar dispositivos de segurança contra os grupos perigosos da sociedade. Esses dispositivos efetivamse a partir do que o autor denomina, em termos biopolíticos, de "racismo de Estado".

Com isso, a criminalização torna-se um meio racional e eficaz para ordenar a sociedade. Essa racionalidade governamental, a fim de garantir a contenção das desordens geradas pelo acirramento da 
exclusão social e pela retração da proteção social, utiliza-se amplamente da estratégia de criminalização dos grupos considerados potencialmente perigosos (WACQUANT, 2001).

O tipo de análise que estou propondo me possibilita assumir que as políticas sociais, de uma forma geral - e da juventude, especificamente -, têm um caráter de ordenamento e normalização, fundando-se em estratégias de segurança pública. Prova disso é o fato de que a maioria das ações propõe como um dos seus objetivos a diminuição da violência.

A "racionalização" das políticas públicas na perspectiva neoliberal, a corrida para os resultados tangíveis contribuem para a marginalização de tais práticas, no final, que ativa a marginalização da prevenção social. Por exemplo, as partes interessadas estão ameaçadas de serem reduzidas a tornarem-se supervisores das populações sobre o risco da delinquência.

É preciso dizer que educar o corpo, cultivar o espírito, controlar as emoções - seja qual for o movimento -, ambos implicam inscrevêlos nas relações de poder, nos códigos culturais. Judith Butler (2001), nesse sentido, esclarece como os corpos são "produzidos" por normas regulatórias que determinam inclusive que lhes sejam atribuídos sexos. Segundo a autora, os corpos têm sua "materialidade" reformulada pelas injunções históricas, de modo a produzir, suportar, sustentar sujeitos e identidades.

É possível reconhecer que as políticas de prevenção dirigidas à juventude pobre são normativas. Mesmo com certo de grau de independência, os/as educadores/as sociais de Grigny Centre prescrevem ou enfatizam normas, significados ou representações de condutas juvenis consideradas adequadas para um determinado tempo e espaço. 
Management of life through sport and leisure in Grigny Centre - France

Abstract: This article is part of doctoral thesis which analyzed certain forms of governamentality of the youth, who use sport and leisure of Grigny Centre (suburban area of Paris). The approach results from the interaction of gender studies and political anthropology, in particular, the perspectives that maintain a critical proximity with Foucault's thinking. The research sources employed were the following: documents press reports; notes from field visits and interviews. Such materials were assessed on the basis of the cultural analysis. Prevention policies targeted to poor youth or prescribe standards emphasize, meanings or representations of juvenile conduct deemed appropriate.

Keywords: Violence. Leisure Activities.

Gestión de la vida mediante el deporte y ocio
en Grigny Centre, Francia
Resumen: El artículo es parte de una tesis doctoral
que ha analizado determinadas formas de
gubernamentalidade la juventud mediante el deporte y
ocio en Grigny Centre (periferia de Paris). El enfoque
del trabajo se ubica en la relación de los estudios de
género y de la antropología política con las
perspectivas que proponen un acercamiento crítico
con la teorización de Michel Foucault. Se han utilizado
como fuentes de investigación los documentos de la
prensa, registros de los diarios de campo y entrevistas.
Los materiales han sido analizados bajo la perspectiva
del análisis cultural. Las políticas de prevención que
utilizan el deporte y ocio buscan prescribir normas,
significados o representaciones de los
comportamientos de los jóvenes que sean
considerados adecuados.
Palabras clave: Violencia. Actividades Recreativas
Políticas de seguridad pública. Gubernamentalidad.
Deporte. Ocio.

\section{REFERÊNCIAS}

ADORNO, Sérgio. O monopólio estatal da violência na sociedade brasileira contemporânea. In: MICELI, Sérgio (Org.). O que ler na ciência social brasileira 1970-2002. São Paulo: Ed. ANPOCS, 2002. v. 4, p. 182-203. 
BRENNER, Ana Karina; DAYRELL, Juarez; CARRANO, Paula. Cultura do lazer e do tempo livre dos jovens brasileiros. In: ABRAMO, Helena Wendel; BRANCO, Pedro Paulo (Org.). Retrato da juventude brasileira: análise de uma pesquisa nacional. São Paulo: Instituto Cidadania/ Fundação Perseu Abramo, 2005. p. 175-214.

BUTLER, Judith. Cuerpos que importan: sobre los límites materiales y discursivos del sexo. Buenos Aires: Paidós, 2001.

CASTEL, Robert. As armadilhas da exclusão. In: CASTEL, Robert; WANDERLEY, Luiz Eduardo; WANDERLEY, Mariângela Belfiore. Desigualdade e a questão social. São Paulo: EDUC, 2007. p. 17-50.

Classes sociais, desigualdades sociais, exclusão social. In: CERTEAU, Michel de. A invenção do cotidiano. Petrópolis: Vozes, 2004.

DAMICO, José Geraldo Soares; MEYER, Dagmar E. Estermann. Constituição de masculinidades juvenis em contextos "difíceis": vivências de jovens de periferia na França. Cadernos Pagu, Campinas, v. 34, p. 143-178, 2010.

DUBET, François. As desigualdades multiplicadas. ljuí: Ed: Unijuí, 2003, 76p.

La galère. Jeunes en survie. Paris: Fayard, 1987.

ELIAS, Norbert. O processo civilizador. Rio de Janeiro: Zahar, 1990. v. 1.

FOUCAULT, Michel. Segurança, território e população. São Paulo: Martins Fontes, 2008.

"O sujeito e o poder". In: RABINOW, Paul; DREYFUS, Hubert. Michel Foucault, uma trajetória filosófica: para além do estruturalismo e da hermenêutica. Rio de Janeiro: Forense Universitária, 1995. p. 231 - 249.

Vozes, 1989.

GASTALDO, Édison. Kickboxers: esportes de combate e identidade masculina. 1995; Dissertação (Mestrado em Antropologia) - Programa de Pós-Graduação em Antropologia Social, Universidade Federal do Rio Grande do Sul, 1995.

HECKTHEUR, Luiz Felipe Alcântara, SILVA, Méri Rosane Santos da. Projetos sociais e esportivos: vulnerabilização e governo. Movimento, Porto Alegre, v. 17, n. 3, p. 115-132, jul./set. 2011.

KOKOREFF, Michel. La force des quartiers: de la délinquance à l'engagement politique. Paris: Payot, 2003.

KURZ, Robert. A ditadura do tempo abstrato: lazer numa sociedade globalizada. São Paulo: SESC/WLRA, 2000.

LAZARUS, Sylvain. Anthropologie du nom. Paris: Editions du Seuil, 1996. 
LEPOUTRE, D. Coeur de banlieue, codes, rites et langages. Paris, Odile Jacob, 1997.

DURAND, Jacky. La machine à expulser ou à exclure. Liberátion, Paris, p. 31-32, 7 juin. 2005.

MACÉ, Eric. As formas da violência urbana: uma comparação entre França e Brasil. Tempo Social: Revista de Sociologia da USP, São Paulo, v. 11, n. 1, p. 177188, maio 1999.

MELO, Marcelo P. de. A Vila Olímpica da Maré e as políticas públicas de esporte no Rio de Janeiro: um debate sobre a relação lazer, esporte e escola. Movimento, Porto Alegre, v. 11, n. 3, p. 89-106, set./dez. 2005.

PERALVA, Angelina. Violência e democracia: o paradoxo brasileiro. São Paulo: Paz e Terra, 2000.

PERCIÚNCULA, Júlio César. "Eles vêm pra cá para se proteger...?" O governamento das crianças do programa SASE do Vida Centro Humanístico em Porto Alegre/RS. 2007. Dissertação (Mestrado em Ciências do Movimento Humano) - Escola de Educação Física, Universidade Federal do Rio Grande do Sul, Porto Alegre, 2007.

THOMASSIM, Luís Eduardo Cunha. Os sentidos da exclusão social na bibliografia da Educação Física brasileira. Movimento, Porto Alegre, v. 10, n. 2, p. 105-122, jan./abr. 2007.

THOMASSIM, Luis Eduardo Cunha; STTIGER, Marco. Super-oferta de projetos sociais esportivos: superando as imagens públicas idealizadas sobre essas ações, 2009. (Apresentação de Trabalho/Comunicação).

VIANNA, José Antonio; LOVISOLO, Hugo Rodolfo. Projetos de Inclusão Social através do esporte: notas sobre a avaliação. Movimento, Porto Alegre, v. 15, n. 3, p. 145-162, jul./set. 2009.

WACQUANT, Löic. As prisões da miséria. Rio de Janeiro, RJ: Jorge Zahar, 2001.

Recebido em: 16.06.2012

Aprovado em: 04.10.2012 